\title{
A new competence-based approach for personalizing MOOCs in a mobile collaborative and networked environment
}

\author{
Un nuevo enfoque basado en competencias para \\ la personalización de MOOCs en un entorno móvil \\ colaborativo en red
}

\author{
António Teixeira \\ José Mota \\ Universidade Aberta (Portugal) \\ Antonio García-Cabot \\ Eva García-Lopéz \\ Luis de-Marcos \\ Universidad de Alcalá (Spain)
}

\begin{abstract}
Massive Open Online Courses (MOOCs) are a disruptive new development in higher education which combines openness and scalability in a most powerful way. They have the potential to widen participation in higher education. Thus, they contribute to social inclusion, the dissemination of knowledge and pedagogical innovation and also the internationalization of higher education institutions. However, one of the critical elements for a massive open language learning experience to be successful is to empower learners and to facilitate networked learning experiences. In fact, MOOCs are designed for an undefined number of participants thus serving a high heterogeneity of profiles, with diverse learning styles and prior knowledge, and also contexts of participation and diversity of online platforms. Personalization can play a key role in this process. The iMOOC pedagogical model introduced the principle of diversity to MOOC design, allowing for a clear differentiation of learning paths and also virtual environments. In this article the authors present a proposal based on the iMOOC approach for a new framework for personalizing and adapting MOOCs designed in a collaborative, networked pedagogical approach by identifying each participant's competence profile and prior knowledge as well as the respective mobile communication device used and to generate matching personalized learning. This paper also shows the results obtained in a laboratory environment after an experiment has been performed with a prototype of the framework. It can be observed that creating personalized learning paths is possible and the next step is to test this framework with real experimental groups.
\end{abstract}

Keywords: framework; adaptation; personalization; learning paths; mobile devices; MOOC. 


\section{Resumen}

Los cursos en línea masivos y abiertos (MOOC) son una nueva tendencia rompedora en la educación superior. Estos cursos combinan la propiedad de ser abiertos con la posibilidad de ser escalables de una forma muy potente. Tienen el potencial de permitir la participación en la educación superior para todas las personas, a todos los niveles. Por lo tanto, contribuyen a la inclusión social, la difusión del conocimiento y la innovación pedagógica, así como la internalización de las instituciones de educación superior. Sin embargo, uno de los elementos críticos para que tenga éxito una experiencia de aprendizaje de forma abierta y masiva es potenciar y facilitar una red de aprendizaje. De hecho, los MOOC no están diseñados para un número predefinido de participantes por lo que sirven para un alto número de perfiles heterogéneos, con diversidad de estilos de aprendizaje y conocimientos previos, pero también contextos de participación y diversidad de plataformas online. La personalización puede desempeñar un papel clave en este proceso. El modelo pedagógico iMOOC introdujo el principio de diversidad en el diseño de MOOC, permitiendo una clara diferenciación de caminos de aprendizaje y también entornos virtuales. En este artículo los autores presentan una propuesta basada en el enfoque de iMOOC, sobre un nuevo sistema para la personalización y adaptación de MOOC diseñados en un enfoque colaborativo y en una red pedagógica. El mecanismo es identificar cada competencia del perfil de los participantes, el conocimiento previo que estos tienen así como detectar sus respectivos dispositivos móviles, y se genera un camino de aprendizaje personalizado en base a estos parámetros. Este artículo también muestra los resultados obtenidos en un entorno de laboratorio después de un experimento llevado a cabo con un prototipo del sistema. Se puede observar que es posible crear caminos de aprendizaje personalizados y que el siguiente paso es probar este sistema con grupos experimentales reales.

Palabras clave: marco; adaptación; personalización; caminos de aprendizaje; dispositivos móviles; MOOC.

The consolidation of a global network society and the subsequent need for rapid, wide and ubiquitous access to quality learning opportunities for everyone has implied a change in our understanding of education. Massive Open Online Courses (MOOCs) represents at best this disruptive new trend that has brought scalability and openness to non formal education. In fact, MOOCs have the potential to widen participation in higher education, thus contributing to social inclusion, the dissemination of innovation and the internationalization of higher education institutions.

MOOCs are so called because they are online courses designed for large number of participants that can be accessed by almost anyone anywhere, as long as they have an internet connection; are open to everyone, since enrolment is free of charge and there are no admission officers or entry qualifications; and offer a full/complete course experience online for free, including social interaction with other learners and limited feedback (McAuley, Stewart, Siemens, \& Cormier, 2010; Saltzman, 2014). In some cases, as with the iMOOC model and the subsequent sMOOC, developed in the framework of the ECO project, MOOCs are also "seamless" because they should 
be accessible from different platforms and through mobile devices and integrate with participants' real life experiences through contextualisation of content and gamifications (Brouns et al., 2014). In this new context, learning has become to be perceived as an increasingly more personalized and flexible, and also a shared and scalable process.

The first MOOC was offered in 2008 (Siemens, 2013), but the concept became widespread in 2012 when several universities started their own MOOCs (Daradoumis, Bassi, Xhafa, \& Caballé, 2013), due to the opportunity to widen the outreach of quality higher education, allowing everone to learn from reputable professors from the top universities at no cost (Sonwalkar, 2013), thus exceeding 100,000 participants in some courses offered by Coursera and Udacity (Siemens, 2013), and/or to take part in a global ecology of knowledge reconstruction.

This first MOOC, CCKo8, was designed according to the connectivist principles of learning (Cormier, 2010; Downes, 2012; Siemens, 2012). Unlike what is typical in academic courses, online or face-to-face, there was not a fixed body of content to be learned, no such roles of "teachers" and "students", or a single location where the course took place. Although there were resources provided as a starting point for the discussion and reflection on the topics defined, content resulted mostly from the production of artefacts by participants (digital objects such as blog posts, presentations, videos, annotated bibliographies, etc.), following their interaction with and their reflection upon the given set of resources (and other resources shared by them or by others), as well as the dialogue among participants around these artefacts; the organizers did not teach, taking the role of facilitators and providers of some necessary structure, especially through an efficient aggregation of the artefacts produced and other material published, with the "teaching" role resting on the learning community itself; and, while there was a course site, with the relevant information (weekly topics, list of suggested resources, synchronous session schedule, etc.) and Moodle forums where people could interact, the conversation was distributed by the participants' own spaces (mostly individual blogs) and several social spaces (Twitter, Facebook, Second Life, etc.).

Several other MOOCs were offered afterwards that followed this approach CCKo9, CCK11, CCK12, Plenk10, Critical Literacies 2010, Change11, LAK11, LAK12, Future of Education 2012, to name a few (Siemens, 2012a) - and consequently MOOCs came to be associated with a connectivist (or connectivist inspired) view on learning, based on a participatory pedagogy and on networked learning.

The pedagogical principles and practices followed by these MOOCs and by those which emerged in 2012, offered by Udacity, Coursera or edX are quite different (Daniel, 2012; Siemens, 2012a; Watters, 2012). So different, in fact, that using the same name to designate them is confusing (Hill, 2012). Downes proposed a useful distinction, calling the former cMOOCs and the latter xMOOCs (Watters, 2012), which has since been widely adopted. While cMOOCs are connectivist in nature and can be said to be "open" as it has been defined in the open education field (OERs, OEPs), 
xMOOCs follow a very traditional approach to learning and use "open" mostly as a synonym for "free of charge" (although even this might change in the near future). They draw on the traditional practices of both face-to-face and distance education courses, ignoring the pedagogical developments, research and innovation in both fields in the past decades. These xMOOCs are focussed on content consumption and reproduction, exhibit the traditional roles of "teachers" and "students", take "lectures" as the primary teaching strategy, rely heavily on video coupled with testing, have a closed, strictly defined curriculum and are highly centralized. In other words, they strive to be a replica, as much as possible, of the traditional classroom, with some potentially innovative elements, such as forums or peer assessment, reduced to serving a traditional academic perspective. As Siemens (2012b) puts it:

Our MOOC model emphasizes creation, creativity, autonomy, and social networked learning. The Coursera model emphasizes a more traditional learning approach through video presentations and short quizzes and testing. Put another way, cMOOCs focus on knowledge creation and generation whereas xMOOCs focus on knowledge duplication.

More recently, a new generation of pedagogical approaches has been emerging mainly in Europe following the iMOOC model and the subsequent sMOOC model. They try to combine the connectivist approach to MOOCs with some elements that can be found in xMOOCs, but used in a different pedagogical context and for different purposes.

The iMOOC pedagogical model, developed at Universidade Aberta (UAb.pt), is the first known institutional model specifically designed for open courses, in particular MOOCs. It started following one fundamental question: how to combine typical non-formal learning experiences with a formal education setting? Instead of trying to replicate an instructional, traditional approach, a more innovative path was taken: to find a synthesis that articulated the potential of networked learning with the structure of higher educational online pedagogy (Teixeira \& Mota, 2015).

Thus, stemming from the already existing UAb's pedagogical model for formal courses and its four pillars - learner-centredness, flexibility, interaction and digital inclusion (Pereira, Mendes, Morgado, Amante, \& Bidarra, 2008) - there was a combination of autonomous and self-directed learning with a strong social dimension and the interaction that make learning experiences richer and more rewarding. There was also the need to articulate the flexibility that distance online learners need, especially adults with demanding professional and personal lives, with the pacing necessary to help them get things done. One of the main objectives was to make learning available to as many people as possible, and also to bring these people into the digital online environment, where a crucial part of modern life happens, thus helping curb the digital divide (Teixeira \& Mota, 2015).

As referred above, the iMOOC model draws mostly on cMOOCs and the general connectivist approach to learning, and incorporates elements from other existing 
approaches, such as short videos, formative tests or peer-assessment, used however, in a different pedagogical context and for different learning purposes. Some other relevant aspects were added that derive from UAb's experience with online learning and its integration in the larger context of UAb.pt's Pedagogical Model, namely a boot camp week, the design of meaningful activities/tasks or effective strategies for online communication, as well as from the work that has been done regarding Open Educational Resources.

The sMOOC pedagogical model was developed in the framework of the European ECO project (Elearning, Communication, Open data), having as one of its objectives the creation of a pan-European alternative to the now dominant xMOOC approach disseminated by elite American universities. It is based on the iMOOC model, which means it draws on connectivism, situated learning and the general socialconstructivist perspective that has always characterized online learning (Brouns et al., 2014). However, because the courses created using this model can have a wide variety of target populations, purposes and local, contextual implementations all over Europe, the model was designed as an open framework to allow for local and contextual choices that make the courses effective. Contextual implemented solutions that seem productive and applicable to other scenarios can enrich the pedagogical practices recommended, by being incorporated into the framework in an ongoing innovative process (Brouns et al., 2014).

These MOOCs are also "seamless" because they should be accessible from different platforms and through mobile devices and integrate with participants' real life experiences through contextualisation of content and gamifications (Brouns et al., 2014). In this new context, learning has become to be perceived as an increasingly more personalized and flexible, and also shared and scalable process.

In fact, designing and running a MOOC involves several logistical, technological, pedagogical and financial issues (Alario-Hoyos, Pérez-Sanagustín, Cormier, \& Kloos, 2014), and precisely one of the characteristics that explains the power of MOOCs is in turn one of the biggest challenges for its design: massiveness (Guàrdia, Maina, \& Sangrà, 2013; Santos, Boticario, \& Pérez-Marín, 2014). Given that MOOCs have the potential to engage a large number of participants in a single course, the heterogeneity of learners is high, i.e. they represent a wider and larger diversity compared with students in traditional courses: there is a higher variety in their maturity level and experience, as well as in their educational and cultural backgrounds, specific knowledge and skills (Daradoumis, et al., 2013; North, Richardson, \& North, 2014); there is also more diversity in intrinsic and extrinsic motivation factors (Teixeira \& Mota, 2013, 2014). But their profile is not the only difference, because they can use different devices to access the courses, e.g. personal computers or mobile devices (Gutiérrez-Rojas, Crespo-García, \& Kloos, 2014), which implies that some formats of learning content may not be displayed while using some devices.

The aforementioned problems can be solved both by a specific pedagogical design strategy, using elements as assessment and accreditation options, for instance 
(Teixeira \& Mota, 2014), and by means of personalization or adaptation of MOOC content to the participants' profiles (prior knowledge) and interaction preferences (device used) (Daradoumis et al., 2013; Santos et al., 2014), which would overcome the problems related to the overwhelming amount of information available and its generation in an open online environment (Fournier, Kop, \& Sitlia, 2011). Moreover, content customization based on user profiling is a desirable characteristic for MOOCs because it enhances the learning process, optimizing the time spent in learning activities and the effectiveness of participation with respect to their individual capabilities (Daradoumis et al., 2013). Therefore, as the education experience should focus on the context-centred processes and not as much on content-driven or container-driven approaches (Cobo, 2014), MOOC learning environments should be able to adapt in relation to the specific learning context. Thus, participants should be able to access specific content, adjusted to the type of media used, establish their own learning sequence, and hence enjoy a unique online experience that supports a quality learning process (Daradoumis et al., 2013).

In this article we present a new framework for personalizing and adapting MOOCs designed in a collaborative, networked pedagogical approach by identifying each participant's competence profile and prior knowledge, as well as the respective mobile communication device used, in order to generate matching personalized learning sequences, recommending an adequate sequence for the participants to organize their learning paths. This article also describes an experiment with a prototype of this framework with simulated learners and real mobile devices. The first section presents the related work, the second section explains the framework design, the third section exhibits the experimentation performed, the fourth section shows the results obtained, and finally, in the last section, the conclusions are drawn.

\section{PREVIOUS RESEARCH}

Adaptation is a recurrent topic in traditional e-learning systems and different concepts have been used for this purpose. To name a few, De Meo et al. (2003) proposed the X-Learn system, which is a multi-agent system that adapts the content according to the user's mobile device, the participant's skills and syllabus; while Andronico et al. (2003) proposed a multi-agent system which includes a module that provides recommendations to the learners based on the preferences of similar learners and on their profile. Trifonova \& Ronchetti (2004) proposed an architecture for supporting mobile devices in LMSs (Learning Management Systems), which has the following functionalities: Context discovery, mobile content management and presentation adaptation, and packaging and synchronization. More recently, Chen, Chen, \& Lin (2008) proposed a framework that provides adaptation when participants change devices to access computer-based learning content, taking into account contextual factors, such as localization. 
However, adaptation is not very developed in MOOCs, where it is even more important because they usually have more participants and their profiles are more varied. As far as the authors know, there is only one study presented in the literature review related to adaptation in MOOCs: a framework and a scalable cloud architecture that use the adaptive mobile learning (AMOL) system and Amazon Web Services to automatically render web pages (Sonwalkar, 2013). This framework uses four dimensions for adapting MOOCs: learning modes (i.e. the format of learning objects), learning pathways (apprentice, incidental, inductive, deductive and discovery learning models), increased interactivity between participant and teachers or facilitators (intelligent feedback, animation, simulations, visualization, games) and social learning (discussion, chat, discourse, presentation). Nevertheless, it does not take into account the participant's competences, i.e. it does not consider the prior knowledge that the learner has; nor does it consider the type of device used.

Furthermore, a framework has also been proposed, which includes the use of software agents to improve and personalize management, delivery and evaluation of massive online courses on an individual level basis (Daradoumis et al., 2013). This framework considers the participants prior knowledge but does not consider the type of device used, which is very important because most MOOCs include lectures formatted as short videos (Glance, Forsey, \& Riley, 2013) and some mobile devices are not able to display them (Passani \& Trasatti, 2004). Furthermore, this framework is only a proposal because it has not been fully developed, so it has not been tested and there are consequently no results about its performance.

The framework proposed in this paper is able to adapt the content of a MOOC to the participant's competences (i.e. prior knowledge) and device. The novelty of the proposal is that the framework adapts to the participant's device, since the current frameworks do not do it, which is very important for mobile devices, because some of them are not able to play some video formats and therefore learners could only follow the course from a computer.

\section{AN ADAPTIVE FRAMEWORK PROPOSAL}

The framework presented in this paper is based on the architecture proposed by (Garcia-Cabot, de-Marcos, \& Garcia-Lopez, 2014; Garcia-Cabot, Garcia-Lopez, de Marcos, Fernandez, \& Gutierrez-Martínez, 2014), and aims to provide adaptation mechanisms for MOOC platforms. As can be seen in figure 1, the participants interact with the MOOC platform using their computer and/or mobile device. The platform is responsible for communicating with the framework in order to obtain a syllabus adapted to the participant's competences and, if necessary, to adapt the (videobased) learning content to the device being used by the participant for training. 
Figure 1. Architecture of the adaptive framework proposed

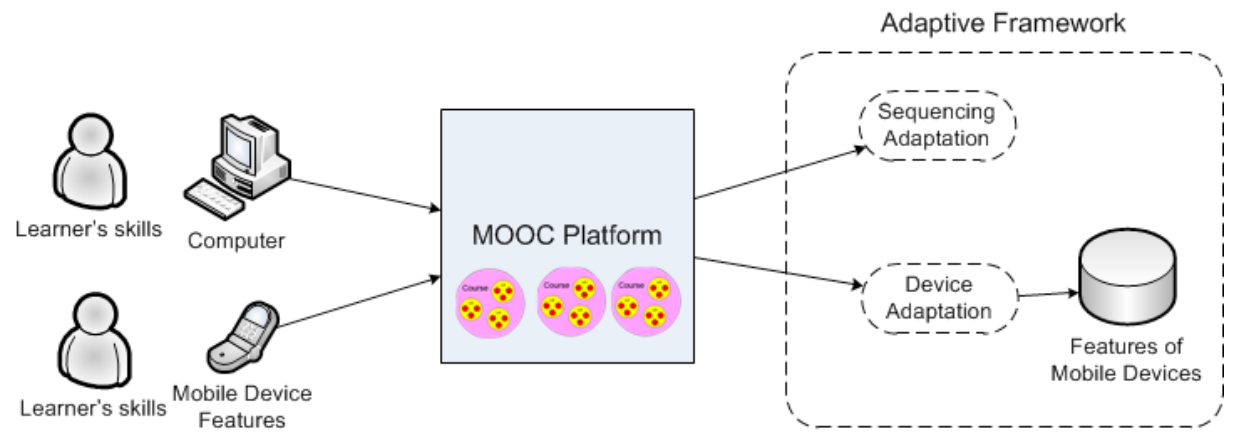

One of the input data considered in the framework is the syllabus offered, as well as prior knowledge relevant for the content in the syllabus. Another input data are the competences that the participant has previously acquired. Finally, to perform adaptation to the device, it is necessary to know which device is being used by the participant to connect to the MOOC platform.

The framework is composed of two intelligent agents: the first one (1) is responsible for creating a learning path personalized for the participant, and the second one (2) performs adaptation based on the characteristics of the participant's mobile device.

The sequencing agent establishes a sequence of tasks that the participant has to complete in order to fully explore the MOOC content. This problem is represented as a Permut-CSP (Constraint Satisfaction Problem) (de-Marcos, Garcia-Cabot, \& Garcia, 2012) where the tasks are the elements to be permuted and prior knowledge and competences are the constraints. The output of this agent is a learning path personalized for the participant, providing a nonlinear experience, not equal for all participants. This might seem to be an easy problem to be solved, but when there is a lot of content it can become a difficult problem to be solved.

Some artificial intelligence techniques have been studied by researchers to solve this problem, e.g., using local and heuristic search, genetic algorithms or PSO (Particle Swarm Optimization) (de-Marcos et al., 2011). The latter (PSO) has been used in the prototype undertaken, since it is one of the fastest to solve the problem (de-Marcos, García, García, Medina, \& Otón, 2011).

The other intelligent agent adapts the learning content to the participant's mobile device. The implementation is relatively simple: based on the User-Agent of the device, the agent searches in repository WURLF (Passani \& Trasatti, 2004) the characteristics of the device the participant is using, and adapts in two senses: (1) if the device does not allow to display some video formats, the learning content is converted to another format compatible with the device; and (2) if the learning 
content is too large to for the device, it is reduced to optimize visualization on the mobile device.

A prototype using the Java programming language has been developed to undertake the experiment with the framework proposed, using a client-server model so that the framework can be easily used by MOOC platforms through web services.

\section{DESIGNING THE CASE STUDY}

A prototype has been developed based on the framework described in the previous section. This prototype is able to carry out the aforementioned functionalities and has been used to perform the case study (experiment). To do this, the MOOC proposed by Garcia-Cabot, Garcia-Lopez, Karhu, \& Teixeira (2014), about creating accessible digital educational content was used. This MOOC has been selected since it applied the iMOOC pedagogical model. As such, its syllabus is diverse and was designed to allow the development of differentiated competence profiles at the end of the learning paths.

\section{The course}

The course "Creating accessible digital educational content" is aimed at teachers conducting online training, and its objective is training teachers to create digital educational content that any participant can use, whether or not they have some kind of physical or sensory disabilities. The course is organized by participants in the cooperation project ESVI-AL (ESVI-AL, 2014), which aims to move towards virtual inclusive Higher Education in Latin America. This course has two versions. One has the format of a workshop, with an online component and a face-to-face one. The second version uses the same resources but is organized as a MOOC (Garcia-Cabot et al., 2014).

We will focus on the MOOC part of this course. The objective of the training courses is to train teachers so they can create digital educational content in a way that is accessible to any participant. Thus, a teacher will be able to create accessible educational content in different formats after finishing the workshop.

Figure 2. Syllabus of the MOOC

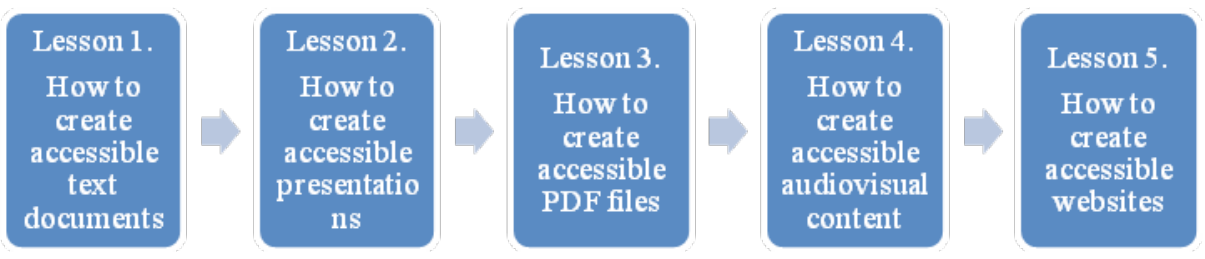


The course is composed of five mandatory lessons. The topics are presented in figure 2, although for the experiment only the first lesson (How to create accessible text documents) will be used.

\section{The case study}

In this case study, one lesson of the MOOC is represented using prior knowledge and competences. Then some participants' profiles are selected and simulated with different competences, and a simulation of the framework is performed to check whether it is able to create different learning paths. The lessons are divided into modules and there is a short video for each module. There are 22 modules in lesson 1 , which are showed in table 1 .

Table 1. Modules and prerequisites of lesson 1 "How to create accessible text documents"

\begin{tabular}{l|l|l}
\hline \multicolumn{2}{l}{ Lesson 1. How to create accessible text documents } & Prerequisites \\
\hline$\#$ & Modules & - \\
\hline 1 & 1.1 Basic concepts & 1.1 \\
\hline 2 & 1.2 Characteristics of an accessible Word document & 1.2 \\
\hline 3 & 2.1 Document structure & 1.2 \\
\hline 4 & 2.2 Language & 1.2 \\
\hline 5 & 2.3 Fonts & $1.2,2.1$ \\
\hline 6 & 2.4 Inserting page numbers in a document & 2.3 \\
\hline 7 & 2.5 Using color & 2.1 \\
\hline 8 & 3.1 Lists, numbered and bulleted lists & 1.2 \\
\hline 9 & 3.2 Table titles & 3.2 \\
\hline 10 & 3.3 Columns and tables & 1.2 \\
\hline 11 & 3.4 Accessible graphs & 1.2 \\
\hline 12 & 4.1 Using blinking elements & 1.2 \\
\hline 13 & 4.2 Navigation links & 1.2 \\
\hline 14 & 4.3 Multimedia elements & $1.2,3.3,3.4,4.3$ \\
\hline 15 & 4.4 Alternative texts & $2.1,2.2,2.4,2.5,3.1,4.4$ \\
\hline 16 & 5.1 Accessibility validation tools & 5.1 \\
\hline 17 & 5.2 Accessibility checking in Office 2010 & 1.2 \\
\hline 19 & 5.3 AccessODF & 1.2 \\
\hline 20 & 5.4 Usability Test & - \\
\hline 21 & 6.2 Converting documents to PDF & - \\
\hline & 6.3 Online validation tools PDFCheck Accesibility Egovmon & - \\
\hline
\end{tabular}


Figure 3. Graph of prerequisites of Lesson 1

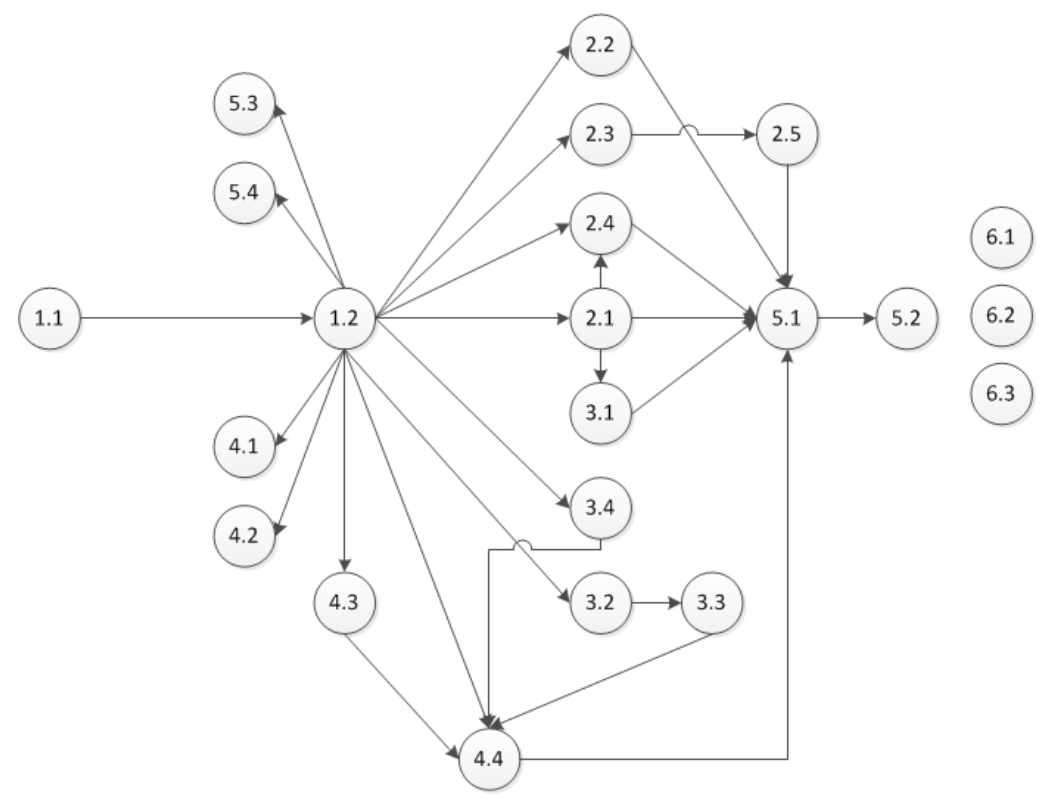

These modules in a traditional MOOC would be linear, so that the participant would start from the first module, then proceed to the next and so on until all lessons have been completed. To create an adapted training, firstly it is necessary to define the competences and the level of prior knowledge of each module, as showed in table 1. A state diagram is used to represent this, so that all the dependencies existing between the modules can be graphically observed (figure 3). If the nodes are connected, it means that the participant has to go through the first module (origin of the arrow) before starting the second one (destination of the arrow).

As seen in figure 3, a participant could start with module 1.1, 6.1, 6.2 or 6.3, because none of them involves prior knowledge. All the other modules depend on previous competences.

\section{RESULTS}

This section presents the results of the case study. First of all, the simulated participants' profiles to be used are described. To undertake the experiment, three different profiles are simulated: (1) a participant with no knowledge of the subject, (2) another participant with some knowledge of the subject and (3) a participant with a medium level of knowledge.

Each participant's competences in relation to lesson 1 are indicated below: 
1. Participant \#1: none.

2. Participant \#2: 1.1, 1.2, 3.2, 2.3.

3. Participant \#3: 1.1, 1.2, 2.1, 2.3, 2.4, 3.1.

Table 2 shows the results obtained after the system has been run and the agent has been executed to create learning paths with each simulated profile. It is important to note that there is not only one solution; these are just a possible solution for each participant.

Table 2. Learning paths created for each participant profile simulated

\begin{tabular}{|c|c|c|}
\hline \multicolumn{3}{|c|}{ Personalized learning paths } \\
\hline Participant \#1 & Participant \#2 & Participant \#3 \\
\hline 1.1 Basic concepts & 2.2 Language & 3.4 Accessible graphs \\
\hline $\begin{array}{l}\text { 1.2 Characteristics of an } \\
\text { accessible Word document }\end{array}$ & $\begin{array}{l}6.2 \text { Converting documents } \\
\text { to PDF }\end{array}$ & 2.5 Using color \\
\hline 2.1 Document structure & 3.3 Columns and tables & 3.2 Table titles \\
\hline 3.2 Table titles & 5.4 Usability Test & 2.2 Language \\
\hline $\begin{array}{l}2.4 \text { Inserting page numbers } \\
\text { in a document }\end{array}$ & 4.2 Navigation links & 4.3 Multimedia elements \\
\hline 4.3 Multimedia elements & 3.4 Accessible graphs & 4.4 Alternative texts \\
\hline $\begin{array}{l}\text { 3.1 Lists, numbered and } \\
\text { bulleted lists }\end{array}$ & 4.3 Multimedia elements & $\begin{array}{l}\text { 6.1 Converting documents to } \\
\text { HTML }\end{array}$ \\
\hline 3.3 Columns and tables & $\begin{array}{l}\text { 6.3 Online validation tools } \\
\text { PDFCheck Accessibility } \\
\text { Egovmon }\end{array}$ & $\begin{array}{l}6.2 \text { Converting documents } \\
\text { to PDF }\end{array}$ \\
\hline $\begin{array}{l}6.2 \text { Converting documents } \\
\text { to PDF }\end{array}$ & $\begin{array}{l}3.1 \text { Lists, numbered and } \\
\text { bulleted lists }\end{array}$ & $\begin{array}{l}5.1 \text { Accessibility validation } \\
\text { tools }\end{array}$ \\
\hline 2.2 Language & $5 \cdot 3$ AccessODF & 4.2 Navigation links \\
\hline 3.4 Accessible graphs & 4.1 Using blinking elements & $5 \cdot 3$ AccessODF \\
\hline 2.3 Fonts & 2.1 Document structure & $\begin{array}{l}5.2 \text { Accessibility checking in } \\
\text { Office } 2010\end{array}$ \\
\hline 2.5 Using color & $\begin{array}{l}2.4 \text { Inserting page numbers } \\
\text { in a document }\end{array}$ & 5.4 Usability Test \\
\hline 4.4 Alternative texts & 4.4 Alternative texts & 3.3 Columns and tables \\
\hline 4.2 Navigation links & 2.5 Using color & 4.1 Using blinking elements \\
\hline 4.1 Using blinking elements & $\begin{array}{l}5.1 \text { Accessibility validation } \\
\text { tools }\end{array}$ & $\begin{array}{l}6.3 \text { Online validation tools } \\
\text { PDFCheck Accessibility }\end{array}$ \\
\hline
\end{tabular}




\begin{tabular}{l|l|l}
\hline Participant \#1 & Participant \#2 & Participant \#3 \\
\hline $\begin{array}{l}\text { 5.1 Accessibility validation } \\
\text { tools }\end{array}$ & $\begin{array}{l}5.2 \text { Accessibility checking in } \\
\text { Office 2010 }\end{array}$ & \\
\hline 5.4 Usability Test & $\begin{array}{l}\text { 6.1 Converting documents to } \\
\text { HTML }\end{array}$ & \\
\hline $\begin{array}{l}\text { 5.2 Accessibility checking in } \\
\text { Office 2010 }\end{array}$ & & \\
\hline 6.1 Converting documents to & & \\
HTML & & \\
\hline 5.3 AccessODF & \\
\hline $\begin{array}{l}\text { 6.3 Online validation tools } \\
\text { PDFCheck Accessibility }\end{array}$ & & \\
Egovmon & \\
\hline
\end{tabular}

As can be seen in the results, a different learning path personalized for each participant's profile has been created. This way participants will not have the same linear experience; it will be personalized based upon their own individual knowledge.

It can also be observed that Participant \# 3 has less modules to complete than Participant \#1. Furthermore, s/he can start with a different module than Participant \#1, who has to start from module 1.1 (the first of all) because he or she does not have prior knowledge about the subject.

The videos for this MOOC were recorded in mp4 format, and a test was conducted in order to check the performance of adaptation to the device. Seven devices were used: Samsung Galaxy Nexus, Samsung Galaxy S3, iPad 2, Tablet Samsung Galaxy Pro, iPhone 4, Nokia Lumia 520 and Blackberry Torch 9860. The results show that all the devices were able to play the videos when using an adequate player.

At other times, MOOC videos are recorded in formats such as flv or similar. These formats are not usually natively supported by mobile devices and need to use an adequate player/plugin or to be converted to another supported format. This is where adaptation to mobile devices is important, so that any participant who uses their device to take part in a MOOC is able to access the content in an appropriate and personalized way.

\section{CONCLUSIONS}

MOOCs have become a very popular type of learning in recent years. This kind of course typically involves thousands of participants with different characteristics, conditions and contexts of use. Such diversification calls for a customization or adaption of course content and learning experiences to participants. There are already some approaches proposed about adaptation of MOOCs, but the contribution of this work is different. It is based on an integrated approach grounded on the iMOOC 
pedagogical model and implies a complete adaptation, not only for the participant personal profile, but also for the mobile devices used. This is an important element as the use of these devices has become commonplace in our network society and it is not surprising that many participants use their personal smartphones or tablets to access the online learning environment. In fact, the use of tablets for this purpose is being reinforced, since they have a larger screen but have the mobility of a reduced device.

Therefore, a framework is proposed which is able to generate suggestions of learning paths adapted to the competences profile of each participant so as to allow for an increased differentiation, personalization and contextualization of learning experiences. The framework also has the ability to adapt the content (usually videos) to the different mobile devices used, so that all participants are able to correctly visualize the content.

In the experiment presented above, it has been demonstrated how MOOCs adapted to participant's competences can be created, as well as how the framework is able to build different learning paths for different simulated participants' profiles. A little test has been described, performed with one lesson of a MOOC, but when applied to a real case (several lessons) the graph of dependencies would be rather too complex to be represented so it is not an easy problem to be solved, and that is why intelligent agents are used.

As it has been demonstrated, the framework proposed works in a laboratory environment, so the next step is to create other experiments in real environments and have experimental groups use the system. In future work, an experimental group with real participants using the same MOOC will be created to investigate how different learning paths are generated and to collect feedback from participants.

\section{ACKNOWLEDGEMENTS}

Authors want to acknowledge the support received from Universidade Aberta and also the University of Lisbon. This research has been funded by the project "Framework motivacional utilizando gamificación y redes sociales en cursos masivos abiertos online" (TIN2014-54874-R), supported by the Ministry of Economy and Competitiveness of Spain.

\section{REFERENCES}

Alario-Hoyos, C., Pérez-Sanagustín, M., Cormier, D., \& Kloos, C. D. (2014). Proposal for a Conceptual Framework for Educators to Describe and Design MOOCs. Journal of Universal Computer Science, 20 (1), 6-23.
Andronico, A., Carbonaro, A., Casadei, G., Colazzo, L., Molinari, A., \& Ronchetti, M. (2003). Integrating a multiagent recommendation system into a mobile learning management system. 
Proceedings of Artificial Intelligence in Mobile System, (pp. 123-132).

Brouns, F., Mota, J., Morgado. L., Jansen, D., Fano, S., Silva, A., \& Teixeira, A. (2014). A Networked learning Framework for Effective MOOC Design: The ECO project approach. Proceedings Eight EDEN Research Workshop - EDEN RW8, (pp. 161-171). Oxford, UK.

Chen, J., Chen, N.-S., \& Lin, T. (2008). Student profile transformation between desktop pcs and mobile phones. International Journal of Engineering Education, 24 (1), 115-126.

Cormier, D. (2010). What is a MOOC? [Youtube video]. Retrieved from www. youtube.com/watch?v=eW3gMGqcZQc

Cormier, D. (2008). The CCKo8 MOOC - Connectivism course, 1/4 way. [Blog post]. Dave's Educational Blog. Retrieved from http://davecormier. com/edblog/2008/10/02/the-ccko8mooc-connectivism-course-14-way/

Daniel, J. (2012). Making Sense of MOOCs: Musings in a Maze of Myth, Paradox and Possibility. Journal of Interactive Media In Education, 3 (o). Retrieved from http://www-jime.open.ac.uk/ jime/article/view/2012-18

Downes, S. (2012). Creating the Connectivist Course. [Blog post]. Half an hour. Retrieved from http://halfanhour. blogspot.pt/2012/01/creatingconnectivist-course.html

Daradoumis, T., Bassi, R., Xhafa, F., \& Caballé, S. (2013). A review on massive e-learning (MOOC) design, delivery and assessment. Proceedings of the 2013 Eighth International Conference on $P_{2} P$, Parallel, Grid, Cloud and Internet Computing (3PGCIC).

de-Marcos, L., Garcia-Cabot, A., \& Garcia, E. (2012). Evolutionary Algorithms to Solve Loosely Constrained Permut-CSPs: A Practitioners Approach. International Journal of Innovative Computing
Information and Control, 8 (7A), 47714796.

de-Marcos, L., García, A., García, E., Medina, J.-A., \& Otón, S. (2011). Comparing the performance of evolutionary algorithms for permutation constraint satisfaction. Proceedings of the 13th annual conference companion on Genetic and evolutionary computation.

de-Marcos, L., Martinez, J. J., Gutiérrez, J. A., Barchino, R., Hilera, J. R., Oton, S., \& Gutiérrez, J. M. (2011). Genetic algorithms for courseware engineering. International Journal of Innovative Computing, Information and Control, 7 (7), 1-27.

De Meo, P., Garro, A., Terracina, G., \& Ursino, D. (2003). X-Learn: an XML-based, multi-agent system for supporting "userdevice" adaptive e-learning. On The Move to Meaningful Internet Systems 2003: CoopIS, DOA, and ODBASE (pp. 739-756). Springer.

ESVI-AL (2014). Virtual Inclusive High Education - Latin America.

Fournier, H., Kop, R., \& Sitlia, H. (2011). The value of learning analytics to networked learning on a personal learning environment. Proceedings of the 1st International Conference on Learning Analytics and Knowledge.

García-Cabot, A., de-Marcos, L., \& GarcíaLopez, E. (2014). An empirical study on m-learning adaptation: learning performance and learning contexts. Computers \& Education.

García-Cabot, A., García-Lopez, E., de Marcos, L., Fernandez, L., \& GutierrezMartínez, J. M. (2014). Adapting Learning Content to User Competences, Context and Mobile Device using a Multi-Agent System: Case Studies. International Journal of Engineering Education, 30 (4), 937-949.

García-Cabot, A., Garcia-Lopez, E., Karhu, M., \& Teixeira, A. (2014). Widening the creation of accessible digital educational 
content: combining a blended learning with a massive open online approach. Proceedings of the Conference of European Distance and E-learning Network.

Glance, D. G., Forsey, M., \& Riley, M. (2013). The pedagogical foundations of massive open online courses. First Monday, 18 (5).

Guàrdia, L., Maina, M., \& Sangrà, A. (2013). MOOC Design Principles. A Pedagogical Approach from the Learner's Perspective. eLearning Papers, 33, 1-6.

Gutiérrez-Rojas, I., Crespo-García, R. M., \& Kloos, C. D. (2014). Adapting an Awareness Tool for Massive Courses: the Case of ClassON. Journal of Universal Computer Science, 20 (1), 24-38.

McAuley, A., Stewart, B., Siemens, G., \& Cormier, D. (2010). The MOOC model for digital practice. Retrieved from http://www.elearnspace.org/Articles/ MOOC Final.pdf

North, S., Richardson, R., \& North, M. M. (2014). To Adapt MOOCS, or Not? That is No Longer the Question. Universal Journal of Educational Research, 2 (1), 69-72.

Passani, L., \& Trasatti, A. (2004). Wireless Universal Resource File (WURFL).

Pereira, A., Mendes, A. Q., Morgado, L., Amante, L., \& Bidarra, J. (2008). Universidade Aberta's pedagogical model for distance education: a university for the future. Lisbon: Universidade Aberta. Retrieved from https://repositorioaberto.uab.pt/ handle/10400.2/2388

Saltzman, G. M. (2014). The Economics of MOOCs. The NEA Almanac of Higher Education.

Santos, O. C., Boticario, J. G., \& PérezMarín, D. (2014). Extending web-based educational systems with personalised support through User Centred Designed recommendations along the e-learning life cycle. Science of Computer Programming, 88, 92-109.

Siemens, G. (2013). Massive Open Online Courses: Innovation in Education? Open Educational Resources: Innovation, Research and Practice, 5.

Siemens, G. (2012a). What is the theory that underpins our moocs? [Blog post]. elearnspace. Retrieved from http://www.elearnspace.org/ blog/2012/06/03/what-is-the-theorythat-underpins-our-moocs/

Siemens, G. (2012b). MOOCs are really a platform. [Blog post]. elearnsapce. Retrieved from http://www.elearnspace. org $/ \mathrm{blog} / 2012 / 07 / 25 /$ moocs-are-reallya-platform

Sonwalkar, N. (2013). The First Adaptive MOOC: A Case Study on Pedagogy Framework and Scalable Cloud Architecture-Part I. Paper presented at the MOOCs Forum.

Teixeira, A., \& Mota, J. (2015). A Proposal For The Methodological Design Of Collaborative Language MOOCs. In E. Martín-Monje, \& E. Bárcena (Ed.), Language MOOCs: Providing Learning, Transcending Boundaries (33-47). Berlin: De Gruyter Open. Retrieved from http://www.degruyter.com/view/ product $/ 455678$

Teixeira, A. M., \& Mota, J. M. (2014). The iMOOC Pedagogical Model: Bridging the gap between non-formal and formal education. Actas del $V$ Congreso Internacional sobre Calidad y Accesibilidad de la Formación Virtual - CAFVIR 2014, (pp. 512-517). Antigua Guatemala, Guatemala.

Teixeira, A., \& Mota, J. (2013). Innovation and Openness through MOOCs: Universidade Aberta's Pedagogical Model for Non-formal Online Courses. Proceedings EDEN Conference 2013, (pp. 479-488). Oslo, Norway.

Trifonova, A., \& Ronchetti, M. (2004). A general architecture to support mobility 
in learning. Proceedings of the IEEE International Conference on Advanced Learning Technologies.

Watters, A. (2012). Top Ed-Tech Trends of 2012: MOOCs. Hack Education.
Retrieved from http://hackeducation. $\underline{\text { com/2012/12/03/top-ed-tech-trends- }}$ of-2012-moocs

\section{PERFIL ACADÉMICO Y PROFESIONAL DE LOS AUTORES}

António Teixeira has a degree (1989), a MPhil (1994) and a PhD (2003) in Philosophy from the University of Lisbon. He teaches at the Open University of Portugal (Universidade Aberta) and is a researcher at the University of Lisbon. He is also the President of the European Distance and E-learning Network and has coauthored the first institutional pedagogical model for MOOCs - the iMOOC. E-mail: antonio.teixeira@uab.pt

Antonio Garcia-Cabot has an MSc (2009) in Computer Science from the University of Alcalá, where he now occupies a researcher position in the Computer Science Department. He finished his PhD (2013) in Information and Knowledge Engineering.

E-mail:a.garciac@uah.es

Eva Garcia-Lopez has a BSc (2007) and a MSc (2009) in Computer Science from the University of Alcalá, where she is now a researcher in the Computer Science Department. She finished her PhD (2013) in Information and Knowledge Engineering.

E-mail: eva.garcial@uah.es

José Mota has a degree in English and American Studies (1989) from the University of Lisbon and a MEd (2009) from Universidade Aberta. He's a researcher at the Distance and eLearning Laboratory - LEaD and has co-authored the iMOOC pedagogical model.

E-mail: josecmota@gmail.com

Luis de-Marcos has a BSc (2001) and an MSc (2005) in Computer Science from the University of Alcalá, where he also completed his PhD in the Information, Documentation and Knowledge program in 2009. He is currently working in the Computer Science Department as an assistant professor.

E-mail: luis.demarcos@uah.es 


\section{DIRECCIÓN DE LOS AUTORES}

University of Alcala

Computer Science Department

School of Engineering

Ctra. Madrid - Barcelona, Km 33,6

Alcalá de Henares - Spain

Universidade Aberta

LEaD - Laboratório de Educação a Distância e eLearning

Palácio Ceia

Rua da Escola Politécnica, 141-147

1269-001 Lisboa - Portugal

Fecha de recepción del artículo: 18/05/2015

Fecha de aceptación del artículo: 16/09/2015

\section{Como citar este artículo:}

Teixeira, A., Garcia-Cabot, A., García-Lopéz, E., Mota, J., y de-Marcos, L. (2016). A new competence-based approach for personalizing MOOCs in a mobile collaborative and networked environment. RIED. Revista Iberoamericana de Educación a Distancia, 19 (1), 143-160. doi: http://dx.doi.org/10.5944/ried.19.1.14578 